\title{
Prevalence of menstrually-related migraine in a population of students from a municipal university center in the interior of Brazil
}

\author{
Isabela Silva Tavares \\ Ariana Pereira Germano \\ Carlos Alberto Bordini
}

Municipal University Center of Franca, São Paulo, Brazil

\section{$\searrow$}

Carlos Alberto Bordini

R. Dr. Manoel Furtado, 410

Centro, Batatais-SP

CEP: 14300-000

Cell phone number:

(16) 992005740

e-mail: cabord@com4.com.br.

\section{Edited by}

Mario Fernando Prieto Peres Marcelo Moraes Valença

Keywords:

Headache

Migraine

Migraine related to menstruation.

\begin{abstract}
Objective

To identify the prevalence of migraine associated to menstruation in a population of students at a college in Brazil's inland.

\section{Methods}

The students were recruited and submitted to the Test for the Identification of Women with Menstrual Period-Related Headache based on the ID-MigraineTM and Menstrual Migraine Assessment Tool questionnaires. Migraine diagnosis was made according to ICHD-3 criteria.

Results

Of the 424 students, $312(73.5 \%)$ answered affirmatively in at least two of the four questions in the first part of the questionnaire and in the following $216(69,2 \%)$ of these reported having migraine related to their menstrual period in the majority of the months.

\section{Conclusions}

Menstrual migraine is a prevalent public health problem that deserves attention in order to ensure a better quality of life for women affected by such a condition.
\end{abstract}




\section{Introduction}

M igraine is a common neurologic disorder with high prevalence, associated to significant disability and impaired quality of life. ' According to The International Classification of the Headaches Third Edition (ICHD-3) migraine belongs to the group of the primary headache disorders. ${ }^{2}$ Its most common form is migraine without aura (ICHD-\# 1.1)., whose diagnostic criteria is depicted in Table 1. According to the 2010 Global Burden of Disease Study (GBD Study), migraine was ranked as the third most prevalent disease in the world2; whist in the 2015 GBD Study, besides, it was ranked third as the biggest cause of inability in men and women at ages under 50 years old.

Table 1. ICHD-3 Diagnostic criteria for Migraine without aura.

\begin{tabular}{|c|c|}
\hline Criterion & Description \\
\hline A & At least five crises fulfilling the criteria of $B$ and $D$ \\
\hline B & $\begin{array}{l}\text { Headache crises during } 4-72 \text { hours (without } \\
\text { treatment or with inefficient treatment) }\end{array}$ \\
\hline C & 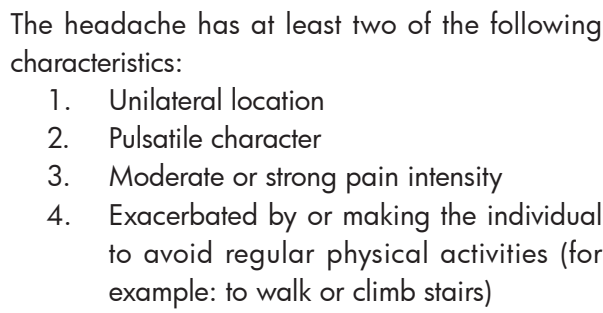 \\
\hline $\mathrm{D}$ & $\begin{array}{l}\text { During the headache, at least one of the following: } \\
\text { 1. Nausea and/or vomiting } \\
\text { 2. Photophobia and phonophobia }\end{array}$ \\
\hline $\mathrm{E}$ & $\begin{array}{l}\text { Not better explained by another diagnosis from } \\
\qquad \text { ICHD-3 }\end{array}$ \\
\hline
\end{tabular}

According to the American Migraine Prevalence and Prevention Study, more than $18 \%$ of adult women suffered from migraine last year. ${ }^{3}$ In a Brazilian study ${ }^{4}$, it was found that the prevalence of headache in one year was $70.6 \% 161.6 \%$ in men and $77.8 \%$ in women). The prevalence of migraine was in $15.8 \%$; (9\% in men and $22 \%$ in women), the prevalence of tensional headache was $29.5 \%$ (28.1\% in men and $30.3 \%$ in women), and the prevalence of daily chronic headache was $6.1 \%$ (3.1\% in men and $8.7 \%$ in women).

Migraine affects mainly during the most productive stages of life, when it is three times more common in women. ${ }^{3}$ The symptoms with moderate to severe intensity are about two times more common in women than in men, thus, affecting their life quality and reducing their work productivity. ${ }^{5}$ The prevalence of migraine is variable according to women hor monal phases during life, it increases at the menarche and thereafter, decreases during pregnancy, it worsens during menstrual periods, in the after child-birth period and during the perimenopause, its prevalence has a trend to be lower in the later phases of life. ${ }^{6}$

The menses are a risk factor for the occurrence of migraine without aura, and even in women that have migraine with aura in other moments of the cycle. ${ }^{7}$ In population studies, between $20 \%$ and $60 \%$ of women with migraine report an association of their crises, at least at some point in life, to their menstruation cycles. ${ }^{7}$

The attacks occurring between two days before the menstruation and during the first three days of bleeding (from -2 to +3 ) are called menstrual migraine. ${ }^{7}$

The menstrual migraine attacks usually have more severe intensity, longer duration (they last for more than 72 hours), increased use of acute medication and usually have higher rate of recurrence as well. ${ }^{8}$ Besides, menstrual migraine attacks are associated to increased impairment in daily activities than non-menstrual migraine attacks. ${ }^{9}$ Women with menstrual migraine show a reduction of $84 \%$ in social performance, with a limitation of $45 \%$ in activities at work, $58 \%$ in familiar activities and $81 \%$ in housework activities. ${ }^{9}$

Although they are recognized as clinic entity, the definitions of migraine related to a menstrual bleeding stage are not well defined so far. ${ }^{7}$ Its diagnostic criteria appear in the Appendix of ICHD-3, (Table 2). In about 10\% of women, migraine attacks occur exclusively during menstruation and in no other moment of the cycle, such condition has been called "pure" menstrual migraine. ${ }^{7}$ For women that experience migraine in other moments of the month, besides the menstruation, it is classified as migraine "related to menstruation". 7 Because of the uncertainty to consider them as distinct entities, the term "menstrual migraine" is often used to involve both conditions; in the appendix of ICHD-3: A 1.1.1 Pure menstrual migraine without aura; A 1.1.2 Migraine without aura related to the menstrual period and A1.1.3 Non-menstrual migraine without aura.'

Table 2. ICHD-3 Diagnostic criteria for migraine without aura related to menstruation.

\begin{tabular}{c|c} 
Criterion & \multicolumn{1}{c}{ Description } \\
A & $\begin{array}{l}\text { Episodes, in a menstruated woman, fulfilling the criteria for } \\
\text { 1.1. Migraine without aura and the criterion B following: }\end{array}$ \\
B & $\begin{array}{l}\text { Occurring in day } 1 \pm 2 \text { (for example: days }-2 \text { to }+3 \text { ) of } \\
\text { menstruation in at least two to three menstrual cycles, and } \\
\text { additionally in other moments of the cycle. }\end{array}$
\end{tabular}


According to MacGregor ${ }^{10}$, menstrual migraine is the one that occurs between 2 days before the first day of menstruation and 2 days after its beginning. The migraine related to the end of menstruation is a common complaint in women that have migraine related to the menstrual period, but it occurs many days after the removal of estrogen, apparently not being mediated by hormonal levels. ${ }^{11}$ Calhoun et al. ${ }^{11}$ believe that this kind of migraine is related to the relative loss of blood, resulting in a short anemia. Moreover, it was recently been demonstrated that the late menstrual phase migraine seems to be related to ferritin levels. ${ }^{11}$

In Brazil, studies on migraine and women are scarcely seen, one of them is the Melhado's one. ${ }^{9}$ Studies on menstrual migraine are uncommon as well, especially in specific populations like female university students. so, due to the scarcity of such studies, we were willing to carry out this one in order to determine the prevalence of migraine related to the menstruation.

\section{Methods}

This study was conducted in a university center located in Franca (Uni-FACEF), in São Paulo state, between August 2019 and December 2020. A quantitative approach, of the transversal and descriptive kind, was used. The recruited participants were female students, 18 - 28 years old attending to the graduation courses, at this university center. This project was approved by the Ethics Committee in Research at Centro Universitário Municipal de Franca (Uni-FACEF) from São Paulo State, with CAAE: 198983 19.7.0000.5384. Female students were asked to agree to a Free and Informed Consent Term prior to participating in the study.
The exclusion criterion was the absence of the student in the college in the days that the questionnaire was applied. They were asked to fulfill a questionary which was read an explained to all of them. Data were collected in a printed and self-applied questionnaire, proposed in two parts, with seven test questions and the possibility of just "yes" and "no" answers, handed in personally to the participants.

The first part of the questionnaire had four questions, the first question being: "Do you use to suffer from headaches?" If the answer was affirmative, the participant would proceed to answer to the next three questions of the validated version in Portuguese of the questionnaire ID-Migraine ${ }^{T M}$, for possible migraine, as published by Gouveia and Martins. ${ }^{12}$ The questionnaire was used without modifications. The second part of the questionnaire had three questions, as proposed in the Menstrual Migraine Assessment Tool, translated to Portuguese $^{13}$ (Table 3).

Individuals were excluded if: 1. Less than two "yes" answers for the first four initial questions; 2. She does not menstruate. Individuals who do not have headache related to her menstrual period were excluded as well. The work up is seen in Figure 1.

The first question of the questionnaire Menstrual Migraine Assessment Tool, used for the elaboration of questions five to seven, answered with a "yes" and at least another one answered with a "yes", from questions two and three, had a

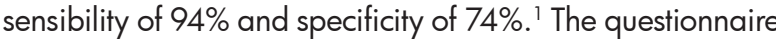
ID-Migraine ${ }^{T M}$, used in questions two, three and four, has a sensibility of $92 \%$, specificity of $60 \%$ and positive predictive value of $93 \% .^{12}$

Table 3. Test for identification of women with headache related to the menstrual period.

\begin{tabular}{|c|c|c|}
\hline Question & \multicolumn{2}{|c|}{ Answers } \\
\hline 1. Do you usually have headaches? & Yes & No \\
\hline $\begin{array}{l}\text { 2. During the last } 3 \text { months, did you have any of the following symptoms together with your headaches: Did you feel } \\
\text { nauseous (with vomiting sensation) while you had the headache? }\end{array}$ & Yes & No \\
\hline $\begin{array}{l}\text { 3. During the last } 3 \text { months, did you have any of the following symptoms together with your headaches: Did the clarity } \\
\text { bother you (much more than when you do not have headaches)? }\end{array}$ & Yes & No \\
\hline $\begin{array}{l}\text { 4. During the last } 3 \text { months, did you have any of the following symptoms together with your headaches: Do your } \\
\text { headaches limit your ability to work, study or do whatever you had to do during, at least, one day? }\end{array}$ & Yes & No \\
\hline \multicolumn{3}{|l|}{ Answer the questions below if you had at least two "yes" answers and if you menstruate } \\
\hline Question & \multicolumn{2}{|c|}{ Answers } \\
\hline
\end{tabular}

5. Do you have headaches related to your menstrual period (that is, do they usually happen between 2 days before the beginning of your period, until three days after it is finished) in most months?

Yes No




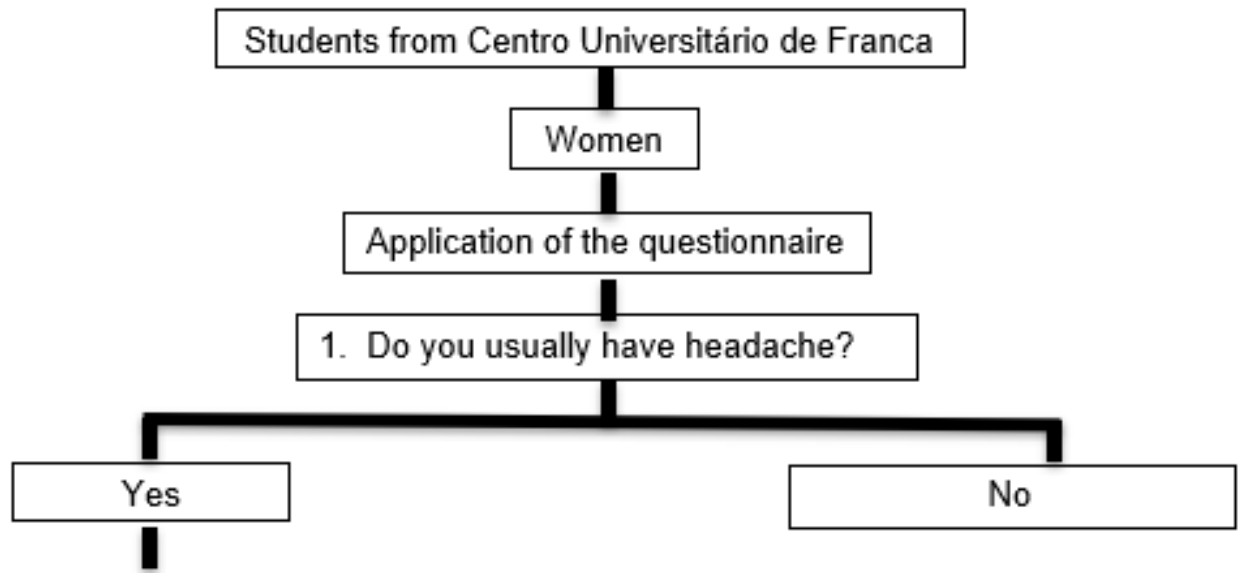

During the last 3 months, did any of the following symptoms occur together with your headaches?

2. Did you feel nauseous (with the vomiting sensation) while you had the headache?

3. Did the clarity bother you (much more than when you do not have headache)?

4. Did your headaches limit your ability to work, study or do whatever you had to do during, at least, one day?

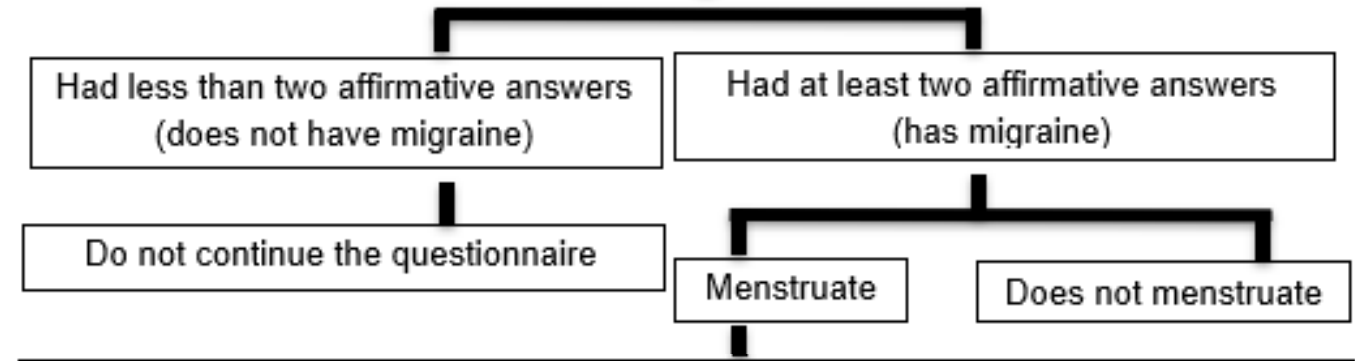

5. Do you have headaches related to your menstrual period (that is, do they usually occur between 2 days before the beginning of your period, until 3 days after it is finished) in most months?

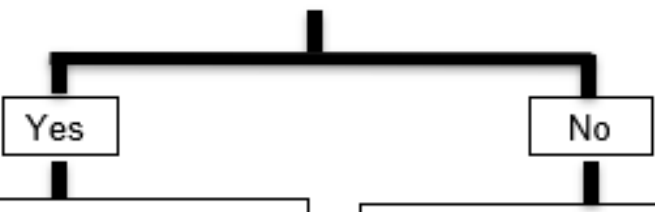

6. Are your headaches usually strong? (Do they stop you from continuing your daily activities)?

7. When you have these headaches, does the clarity bother you more than when you do not have headache?

Do not continue the questionnaire, because the person does not have migraine related to menstruation

\section{The person has migraine related to menstruation}

Figure 1. Flow chart for the identification of menstrual migraine 
The compiled of data obtained from the printed questionnaire was done through the online tool Google Forms ${ }^{T M}$, in which the answers were transcribed without any modifications to the inserted questionnaire in the platform, identical to the printed questionnaire. In the statistical analysis of the results, the calculations were done with the Google Forms software ${ }^{T M}$.

\section{Results}

The total of female students, enrolled and that to participate according to the Free and Informed Consent Term were 424. Out of this number, $312(73.5 \%)$ answered affirmatively in at least two of the four questions of the first part of the questionnaire. Therefore, the prevalence of migraine in this population is $73.5 \%$ (Table 4).

Table 4. Prevalence of migraine in women from in the student population $(n=424)$.

\begin{tabular}{|c|c|c|}
\hline Question & $\begin{array}{c}\text { Yes n } \\
(\%)\end{array}$ & $\begin{array}{c}\text { No n } \\
(\%)\end{array}$ \\
\hline 1. Do you usually have headaches? & $\begin{array}{c}316 \\
(74.5 \%)\end{array}$ & $\begin{array}{c}108 \\
(25.5 \%)\end{array}$ \\
\hline $\begin{array}{l}\text { 2. During the last } 3 \text { months, did you have any of the } \\
\text { following symptoms together with your headaches: } \\
\text { Did you feel nauseous (with vomiting sensation) } \\
\text { while you had the headache? }\end{array}$ & $\begin{array}{c}253 \\
(59.6 \%)\end{array}$ & $\begin{array}{c}171 \\
(40.4 \%)\end{array}$ \\
\hline $\begin{array}{l}\text { 3. During the last } 3 \text { months, did you have any of the } \\
\text { following symptoms together with your headaches: } \\
\text { Did the clarity bother you (much more than when } \\
\text { you do not have headaches)? }\end{array}$ & $\begin{array}{c}265 \\
(62.5 \%)\end{array}$ & $\begin{array}{c}159 \\
(37.5 \%)\end{array}$ \\
\hline $\begin{array}{l}\text { 4. During the last } 3 \text { months, did you have any of the } \\
\text { following symptoms together with your headaches: } \\
\text { Did your headaches limit your ability to work, study } \\
\text { or do whatever you had to do during, at least, } \\
\text { one day? }\end{array}$ & $\begin{array}{c}235 \\
(55.5 \%)\end{array}$ & $\begin{array}{c}189 \\
(44.5 \%)\end{array}$ \\
\hline
\end{tabular}

In the second part, out of 312 women with migraine, 216 $(69.2 \%)$, or $50.9 \%$ of the total population were found to have menstrual migraine (Table 5).

Table 5. Prevalence of migraine related to the menstrual period in women from in the student population $(n=312)$.

\begin{tabular}{|c|c|c|}
\hline Question & $\begin{array}{l}\text { Yes } n \\
(\%)\end{array}$ & $\begin{array}{l}\text { No } n \\
(\%)\end{array}$ \\
\hline $\begin{array}{l}\text { 5. Do you have headaches related to your menstrual } \\
\text { period (that is, do they occur regularly between } 2 \\
\text { days before the beginning of you period, until } 3 \\
\text { days after it is finished) in most months? }\end{array}$ & $\begin{array}{c}216 \\
(69.2 \%)\end{array}$ & $\begin{array}{c}96 \\
(30.8 \%)\end{array}$ \\
\hline $\begin{array}{l}\text { 6. Are your headaches usually severe? (Do they stop } \\
\text { you from continuing your daily activities)? }\end{array}$ & $\begin{array}{c}159 \\
(50.9 \%)\end{array}$ & $\begin{array}{c}153 \\
(49.1 \%)\end{array}$ \\
\hline $\begin{array}{l}\text { 7. When you have these headaches, does light } \\
\text { exposure bother you more than when you do not } \\
\text { have headache? }\end{array}$ & $\begin{array}{c}235 \\
(75.3 \%)\end{array}$ & $\begin{array}{c}77 \\
(24.7 \%)\end{array}$ \\
\hline
\end{tabular}

\section{Discussion}

This study showed that $73.5 \%$ of the female students from this population have migraine and, $50.9 \%$ of them have migraine related to the menstrual period. In a similar study with 204 teenagers (average age of $14.0 \pm 1.4$ ), the prevalence of migraine without aura related to menstruation was found at $6.7 \% .^{15}$ The discrepancy of data may be due to maybe that in the population, younger women, many of them in a prepuberal age. It is well known that there is a significant increase in the prevalence of migraine following puberty. ${ }^{16}$

In another retrospective study in a sample of 896 girls between 9 and 18 years old, it was found that 331 (50.3\% of girls in the menarche and $36.9 \%$ of all girls) was deemed to have migraine, out of this number, $63.6 \%$ reported migraines during the days -2 to +3 of the beginning of the menstrual period. ${ }^{17}$ These findings are similar to ours.

As a limitation of this study is that it was carried out in a very specific population, therefore generalizations may not be withdrawn.

On the other hand it was demonstrated the high prevalence of migraine in female university students, with possible impact in their quality of life, and demanding concerns from Public Health System. Thus, further studies about this topic are necessary in order to confirm our findings and in such cases to take actions to diminish the suffering of these people.

\section{Conflict of interests: No}

Isabela Silva Tavares

https://orcid.org/0000-0002-6407-3773

Ariana Pereira Germano

https://orcid.org/0000-0003-0500-6228

Carlos Alberto Bordini

https://orcid.org/0000-0002-1249-5202

\section{References}

1. Arnold MJC. Headache classification committee of the international headache society (IHS) the international classification of headache disorders. 2018;38(1):1-211

2. James SL, Abate D, Abate KH, Abay SM, Abbafati C, Abbasi $N$, ... Abdela J. Global, regional, and national incidence, prevalence, and years lived with disability for 354 diseases and injuries for 195 countries and territories, 1990-2017: a systematic analysis for the Global Burden of Disease Study 2017. 
The Lancet 2018;392:1789-1858 Doi: 10.1016\%2FS01406736(18)32279-7

3. Queiroz LP, Peres MF, Piovesan EJ, Kowacs F, Ciciarelli MC, Souza JA and Zukerman E. A nationwide population-based study of migraine in Brazil. Cephalalgia : an international journal of headache 2009;29(6):642-649 Doi: 10.1111/j.14682982.2008.01782.x

4. Queiroz LP and Silva Junior AA. The Prevalence and Impact of Headache in Brazil. Headache 2015;55(Suppl 1):32-38 Doi: 10.1111/head. 12511

5. Ferreira KS, Bolinelli LP and Pagotto LC. Migrânea e sincronização de ciclo menstrual em mulheres: existe uma relação? Relato de caso. Revista Dor 2015; 16:156-158 Doi: 10.5935/1806-0013.20150030

6. Faubion SS, Batur P and Calhoun AH Migraine Throughout the Female Reproductive Life Cycle. Mayo Clinic proceedings 2018;93(5):639-645 Doi: 10.1016/i.mayocp.2017.11.027

7. MacGregor EA. Progress in the Pharmacotherapy of Menstrual Migraine. Clinical Medicine Insights: Therapeutics 201 1;3:245273 Doi: 10.4137/CMT.S6170

8. Allais $G$ and Benedetto $C$. Update on menstrual migraine: from clinical aspects to therapeutical strategies. Neurological sciences: official journal of the Italian Neurological Society and of the Italian Society of Clinical Neurophysiology 2004;25(Suppl 3)229-231 Doi: 10.1007/s10072-004-0292-6

9. Melhado EM. Enxaqueca na mulher. Enxaqueca Em Pauta Revista da Novartis 2020; 1:6-8

10. Miziara L, Bigal ME, Bordini CA and Speciali JG. Cefaleia menstrual: estudo semiológico de 100 casos. Arquivos de
Neuro-Psiquiatria 2003;61(3A):596-600 Doi: 10.1590/ S0004-282X2003000400013

11. Calhoun AH and Gill N. Presenting a New, Non-Hormonally Mediated Cyclic Headache in Women: End-Menstrual Migraine. Headache 2017;57(1):17-20 Doi: 10.1111/head. 12942

12. Mattos A, Souza JA, Moreira PFF, Jurno ME and Velarde LGC. ID-Migraine ${ }^{\mathrm{TM}}$ questionnaire and accurate diagnosis of migraine. Arquivos de neuro-psiquiatria 2017;75(7):446-450 Doi: 10.1590/0004-282×20170069

13. Tepper SJ, Zatochill M, Szeto M, Sheftell F, Tepper DE and Bigal M. Development of a Simple Menstrual Migraine Screening Tool for Obstetric and Gynecology Clinics: The Menstrual Migraine Assessment Tool. Headache 2008;48(10):1419-1425 Doi: 10.1111/j.1526-4610.2008.01304.x

14. Tepper SJ, Zatochill M, Szeto M, Sheftell F, Tepper DE. Development of A Simple Menstrual Migraine Screening Tool. Headache Headache 2008;48(10):1419-1425 Doi: 10.1111/j.15264610.2008.01304.x

15. Lima AS, Araújo RC, Gomes MRA, Almeida LR, Souza GFF, Cunha SB and Pitangui ACR. Prevalência de cefaleia e sua interferência nas atividades de vida diária em adolescentes escolares do sexo feminino. Revista Paulista de Pediatria 2014;32(2):256-261 Doi: 10.1590/01030582201432212113

16. Aquino JHW, Fortes FM. Cefaleias na adolescência. Revista adolescência e Saúde 2009;6(3)

17. Crawford MJ, Lehman L, Slater S, Kabbouche MA, Lecates SL, Segers A, ... Hershey AD. Menstrual migraine in adolescents. Headache 2009;49(3):341-347 Doi: 10.1111/j.15264610.2009.01347.x 